\title{
ESTETIKA SUFISTIK DAN ESTETIKA TAUHIDIK: PERSPEKTIF FILOSOFIS KOMPARATIF
}

\author{
Muh Farkhan $\mathrm{M}^{1,2}$ \\ ${ }^{1}$ Program Studi Sastra Arab Fakultas Ilmu Budaya \\ Universitas Sebelas Maret Surakarta \\ 22Email:mfarchan3@gmail.com
}

\begin{abstract}
This article discusses the concept of Islamic aesthetics, which is the view of art and beauty according to Ismail Raji Al Faruqi and Seyyed Hossein Nasr, the representation of the two intellectual figures is seen as representing a pattern of religious understanding, especially with regard to the perspective of art objects in Islam. The aim is to explain descriptively the comparative views of the two modern Islamic thinkers and examine how Muslims respond to their thoughts in the Islamic art world today. furthermore, the article explain conceptually how religious art thought is believed and chosen as a basis in determining the direction and expression of art in the socio-cultural space. The method used in this study is descriptive qualitative analytic, with a religious philosophical approach to Islam, while data collection techniques are carried out through literature that is described qualitatively. The results show that aesthetics built on Sufistic conception and spiritual appreciation so distinctively in it's paradigm. The Sufistic paradigm emphasize how art is able to strengthen one's psyche without debating legal status, while monotheistic aesthetics built on the basis of the legal text and dogmatism emphasize the exoteric level as legally considered by Islamic Islamic law. Thus the social responsibility and the selection of aesthetic views are sectarian in accordance with their religious beliefs.
\end{abstract}

Keywords: Islamic Aesthetics, Sufism, Sectarian.

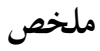

$$
\begin{aligned}
& \text { يناقش هذا المقال مفهوم الجماليات الإسلامية، وهي من وجهة نظر الفن والجمال، وفقًا لإسماعيل راجي الفاروقي } \\
& \text { وسيد حسين نصر، فإهما يمثلان نمط الفهم الديني، لا سيما فيما يتعلق بممتلكات التحف الفنية في الإسلام، } \\
& \text { ويهدف إلى شرح نقاط تفكيرهما ودراسة كيفية استجابة المسلمين لأفكارهما في عالم الإسلام الحديث وشرح كيف } \\
& \text { يعتقد فكر الفن الديني ويتم اختياره كقاعدة نموذجية في تحديد ابتحه الفن والتعبير عنه في الوسط الاجتماعي والثقافي. } \\
& \text { الطريقة المستخدمة في هذا البحث هي وصفية تحليلية نوعية، مع النهج الفلسفي الإسلامي، في حين يتم تنفيذ } \\
& \text { تقنيات جمع البيانات من خلال الأدب الموصوف نوعيا. أظهرت النتائج أن الجماليات المبنية على التصوف والقدرة } \\
& \text { الروحية تؤكد على قدرة الفن التصوفي على تقوية نفسيته دون مناقشة الوضع القانوني، و في حين اخر تؤكد } \\
& \text { الجماليات التوحيدية المبنية على أساس النصوص القرانية ولاحاديث النبوية تؤكد الشريعة الاسلامية وبالتالي فإن } \\
& \text { المسؤولية الاجتماعية واختيار الآراء الجمالية طائفية وفقًا لمعتقداتم الدينية. } \\
& \text { الكلمات المفتاحية: الجماليات الإسلامية ، الصوفية ، الطائفية }
\end{aligned}
$$




\section{A. Pendahuluan}

Dalam khazanah pemikiran Islam kajian tentang seni dan keindahan merupakan bagian penting di antara diskursus pemikiran yang lain, meskipun tensi para pemikir muslim tidak sama mendalam dengan cabang-cabang lain seperti akidah, muamalah, dan akhlak. Diskursus tentang pemikiran seni dan keindahan Islam yang selama ini kurang mendapatkan perhatian secara serius dan mendasar ini antara lain disebabkan karena umat Islam belum memfokuskan diri secara kritis. Fokus umat muslim terhadap estetika belum tercurah secara mendalam karena perhatian mereka pada saat itu masih terfokus pada masalah yang lebih urgen dan krusial dan membutuhkan jawaban-jawaban kritis serta pasti bagi kelangsungan kehidupan beragama. Masalah seni masih dipandang sebagai pelengkap bagi kesempurnaan (mashlachah tachsiniyah) dalam menjalankan peran kemanusisan dan keberagamaan (Tim Penulis, 1995:199).

Perhatian pada masalah akidah merupakan kebutuhan fundamental yang harus tetap terjaga seiring dengan perhatian pada bidang muamalah dan akhlak namun sebenarnya masalah seni budaya dan nilainilai keindahan yang melekat di dalamnya tidak bisa dipandang sebagai pelengkap karena runtuhnya landasan dan bangunan estetika bisa menjadi penyebab runtuhnya bangunan moral dan aqidah itu sendiri. Ini bukan sekedar suatu peralihan tingkatan atau kebutuhan di dalam maslahahmaslahah hidup bagi orang-orang Islam namun suatu kesatuan amaliah menuju keberagamaan yang sempurna dan kaffah.

Persoalan seni estetik yang semula bersifat tachsiniyah atau kebutuhan yang bersifat tambahan meningkat menjadi kebutuhan yang bersifat dharuriyah atau kebutuhan yang sifatnya penting dalam peningkatan keberagamaan, dan karena sifatnya krusial maka bidang kajian estetika juga membutuhkan pemecahanpemecahan secara keilmuan fiqhiyahijtihadiyah dan yang pasti sesuai dengan keyakinan masyarakat. Sikap ini tentu sangat berbeda dengan keadaan saat
Rasulullah SAW masih hidup, yaitu ketika semua persoalan yang berhubungan dengan seni langsung mendapatkan putusan hukum, sehingga para sahabat dapat melakukan kreatifitas sesuai dengan petunjuk-petunjuk keagamaan langsung di bawah bimbingan beliau. Persoalan interpretasi dan ijtihad nampaknya yang membedakan hal ini dengan masa-masa kenabian meskipun ayat-ayat dan hadis tentang seni di dalam sumber hukum Islam telah jelas disebutkan.

Dalam sejarah pemikiran Islam modern, penafsiran terhadap seni dan keindahan nampak tersekat ke dalam kesadaran-kesadaran subjektif dan perbedaan dimensi sudut pandang, namun seringkali pandangan-pandangan dunia Islam tidak memainkan peran kunci dalam penilaian estetis orang atas objek-objek seni yang dikreasikan di dunia Islam, tidak ada sejenis kesadaran tertentu yang dibutuhkan untuk mengapresiasi seni Islam (Leaman, 2004). Sejarah pemikiran seni Islam dapat dikatakan kurang tanggap terhadap respon perkembangan zaman padahal dunia intelektual sangat membutuhkan pencerahan, solusi dan alternatif-alternatif pijakan dan landasan berkreasi. Beberapa ide estetika Islam modern yang cukup kuat merespon perkembangan zaman antara lain gagasan dalam penelitian ini, sedangkan dalam lingkup wilayah tertentu, di Indonesia misalnya lembaga seni budaya dan olahraga pimpinan Pusat Muhammadiyah nampaknya telah berupaya merespon problem seni budaya secara moderat melalui jurnal kajian seni budaya Islam. Setidaknya hal ini turut merespon perkembangan-perkembangan isu-isu di dunia seni kontemporer. Kajian seni budaya dalam tradisi keagamaan di Indonesia nampaknya memilih alternatifalternatif sesuai dengan paradigma keilmuan (ijtihad) dan keyakinan yang ditetapkan di dalam khiththah lembaga keagamaan masing-masing. NU nampaknya berusaha merumuskan dan mengembangkan "fiqh kebudayaan" yang mampu menjaga, memelihara, menginspirasi dan memberi orientasi bagi 
pengembangan kreativitas masyarakat pada wilayah kebudayaan dalam rangka pemenuhan kodratnya sebagai khalifah fil ardl dan sekaligus warga masyarakatbangsanya (anggamardiansyah.blogspot.com akses). Pada wilayah praktis akulturasi, seni-budaya lokal di Indonesia menjadi bagian dari telaah sosio estetika Islam dengan pendekatan apapun. Kajian terhadap peninggalan budaya tangible berupa bangunan makam, masjid, keraton, maupun peninggalan yang bersifat intangible seperti adat istiadat dan kesenian, menjadi bagian dari akulturasi budaya Islam dengan budaya lokal. Peninggalan budaya Islam terkait juga dengan aspek religi dalam bentuk sinkretisme (Mansyur, 2016: 45)

\section{B. Metodologi Penelitian}

Artikel ini mengemukakan model pemikiran dalam sudut pandang berbeda antara dua tokoh intelektual muslim modern: Ismail Raji Al Faruqi dan Seyyed Hossein Nasr. Penelitian ini bersifat deskriptif komparatif kualitatif yaitu mendeskripsikan ide dan model pemikiran estetika Islam modern dari dua pemikir Islam tersebut dalam bentuk perbandingan dalam satu topik penelitian dan data primer yang berbeda untuk diarahkan dalam satu bentuk sintesis, atau setidak-tidaknya dapat mempertahankan pendapat masing-masing sesuai dengan argumentasi yang diberikan (Sumantri, 2001:69). Selain itu ertikel ini juga merupakan pengembangan dari metode deskriptif yang mengungkapkan gagasan seseorang disertai dengan kritik dan analisis yang bersifat kritis. Asumsinya adalah semua gagasan manusia tidak sempurna, dan dalam ketidaksempurnaan itu terkandung kelebihan dan kekurangan. Objek material dalam penelitian ini adalah pemikiran estetika dua tokoh pemikir Islam modern tersebut, sedangkan objek formalnya adalah visi dan pandangan filosofis keagamaan mengenai hakikat seni, keindahan, dan norma-norma yang berkaitan dengannya.

Data penelitian diperoleh dari data primer, yaitu naskah yang memuat karangan asli kedua tokoh; dan kedua adalah data sekunder, yaitu naskah yang memuat gagasan mereka yang diterbitkan oleh orang lain dalam bentuk buku, jurnal, artikel, hasil penelitian atau makalah. Prosedur memperoleh dan menganalisis data dalam penelitian ini adalah dengan mengumpulkan data primer yang terdiri atas sejumlah karya Al Faruqi dan Nasr. Ide-ide mereka tentang estetika Islam dideskripsikan dan dianalisis dengan memperhatikan pengaruh timbal balik dan berkaitan, selanjutntya dilakukan penafsiran, yaitu mengubah gagasangagasan yang tidak dimengerti menjadi dimengerti sesuai dengan konteks peneliti (Sumaryono, 1999: 24).

\section{Kerangka Teori}

Perbincangan tentang estetika seringkali dikaitkan dengan pengalaman di samping pemahaman tentang objek-objek keindahan maupun kejelekan. Definisi estetika yang memuat proses estetis disampaikan oleh Mandoki dalam Everyday Aesthetics, yaitu sebuah studi tentang proses estetis sebagai "suatu proses yang dialami subjek sebagai makhluk hidup saat membuka dan menerima dunia.“ (Junaeidi, 2017:21), suatu konsep pemikiran yang luas terkait dengan pengalaman atau proses pencapaian seseorang terkait dengan nilai-nilai keindahan. Dalam prosesnya, pencapaian itu selalu dipengaruhi oleh pemikiran, ideologi, atau keyakinan-keyakinan. Dalam Islam proses pencapaian nilai-nilai keindahan itu juga dipengaruhi oleh model, corak pemahaman, aliran atau mazhab yang berkembang di dalamnya.

Artikel penelitian ini didasarkan pada dua kerangka teori. Pertama, pandangan teoritis dari tauhid sebagai prinsip-prinsip rasional tentang pencipta dan ciptaan, pemahaman objek-objek alam, kebertujuan suatu penciptaan (teleologi), kekhilafahan manusia, dan etika. Prinsip-prinsip ini digunakan sebagai landasan Islamisasi. Kedua, pandangan Neo Platonik, bahwa keindahan sebagai sesuatu yang memiliki latar belakang kausalitas, yang ia sebut dengan "The One", atau realitas pertama yang ada di balik dunia nyata (invisible), yaitu puncak dari segala realitas keindahan. 
Plotinus menyebutnya pula sebagai the

Hypostatis. Realitas kedua adalah intellect, atau pikiran yang dapat mengetahui segala sesuatu, dan yang ketiga adalah jiwa all-soul atau prinsip kreativitas dan kehidupan. Selanjutnya melalui tahap emanasi ketiga realitas tersebut Plotinus mengembangkan teori keindahan yang dianggap sebagai orisinalitas tertinggi (Hospers, 1967:39).

\section{Pembahasan}

\section{Biografi Ismail Raji Al Faruqi}

Dia adalah seorang tokoh intelektual sekaligus pejuang Islam yang lahir di Jaffa Palestina pada 1 Januari 1921, pendidikannya dimulai dari sekolah dasar dan menengah di Lebanon pada tahun 1926-1936, kemudian melanjutkan di American University of Beirut pada tahun 1941, karir pekerjaannya dimulai sebagai pegawai pemerintahan Palestina di bawah mandate Inggris selama kurang lebih empat tahun. Pada tahun 1947 ketika Israel menduduki wilayah Galilea, Al Faruqi pindah ke Amerika untuk mengubah haluan hidupnya ke dunia akademis. Di sana ia melanjutkan studinya yang sempat terhenti. Al-Faruqi melanjutkan studinya di Indiana University pada tahun 1948, hingga mencapai gelar mater dalam bidang filsafat. Dua tahun berikutnya ia kembali memperoleh gelar master di Harvard University, juga dalam bidang falsafat. Untuk memperdalam keislaman, empat tahun berikutnya ia menimba ilmu di AlAzhar University, Kairo Mesir. Selama beberapa tahun kemudian ia menjadi Profesor tamu untuk studi keislaman di McGill University (1958-1961) dan di Pana Central institute of Islamic Research, Karachi, menjadi tamu untuk studi ilmu sejarah dan ilmu agama di the University of Chicago, sebagai lektor kepala llmu agama pada Saracus University (1964-1968). Pada masa hayatnya, al-Faruqi pemah memegang jabatan penting dalam kapasitasnya sebagai ilmuan. Diantaranya adalah kepala studi keislaman di Temple University, AS; Direktur Institut Islam di University Chicago; Direktur Institut Intemasional pemikir Islam do
Washington; dan presiden Institu studi Lanjutan Washington. Semangat kritik ilmiahnya dan kecakapan dalam bidang keilmuan membuat Al-Faruqi mengemukakan ide perlunya mengislamkan ilmu-ilmu sosial kontemporer. Untuk mencapai tujuan ini ia mendirikan Himpunan Ilmuan Sosial Muslim (The Assosiation of muslim Social Scientists). Ia menjadi presiden yang pertama pada tahun 1972 hingga 1978. AlFaruqi juga berperan penting dalam pembentukan lembaga Internasional (The Intenational Institute if Islamic Thought). Kedua lembaga tersebut secara bersamasama menerbitkan jurnal American Journal of Islamic Social Sciences. Al-Faruqi adalah ilmuan yang produktif. Ia berhasil menulis lebih dua puluh buku dan seratus artikel. diantara bukunya yang terpenting adalah Tauhid: its Implications for Thought and file (1982). Buku ini mengupas tentang tauhid secara lengkap. Tauhid tidak hanya dipandang sebagai ungkapan lisan bahkan lebih dari itu, tauhid dikaitkan dengan seluruh aspek kehidupan manusia, baik itu segi politik, sosial, ekonomi, seni dan budaya. (https://www.referensimakalah.com )

\section{Biografi Seyyed Nossein Nasr}

Seyyed Hossein Nasr lahir di kota Teheran, Iran, pada tanggal 7 April 1933. Ayahnya bernama Seyyed Waliyullah Nasr. Beliau adalah seorang ulama besar sekaligus menjabat sebagai guru dan dokter pada masa dinasti Qajar kemudian di angkat sebagai pejabat setingkat menteri pada masa dinasti Reza Syah. Gelar Seyyed adalah sebutan kebangsawanan yang dianugerahkan oleh raja Syah Reza Pahlevi kepada keduanya. Keluarga Nasr adalah penganut aliran Syi'ah tradisional yang menjadi aliran teologi Islam. Aliran ini banyak dianut dan didominasi oleh penduduk Iran sampai sekarang, walaupun telah terjadi revolusi di sana. Hal ini disebabkan karena paham Syi'ah telah lama hidup di sana. Di samping itu juga karena didukung oleh banyak ulama terkenal dan berpengaruh. Nasr memperoleh pendidikan tradisional di Iran pada usia 13 tahun. Pendidikan tradisional 
ini diperoleh secara informal dan formal. Pendidikan informalnya dia dapat dari keluarga, terutama dari ayahnya, sedangkan pendidikan tradisional formalnya diperoleh di madrasah Teheran. Selain itu dia juga dikirim oleh ayahnya untuk belajar filsafat, teologi, dan tasawuf di madrasah pendidikan yang bertempat di Qum. Allamah Thabathaba'i adalah pengasuh madrasah tersebut. Ia juga diberi pelajaran tentang hafalan al-Quran dan pendidikan tentang seni Persia klasik dan sufisme (widodosyukronfa.blogspot.com). Obsesi Waliyullah Nasr kepada Hossein Nasr adalah agar menjadi orang yang memperjuangkan kaum tradisional dan nilai-nilai ketimuran. Hal ini dimulai dengan memasukkkan Hossein Nasr ke Peddie School di Hightstown, New Jersey, Amerika Serikat. Ia lulus pada tahun 1950. Kemudian melanjutkan ke Massacheusetts Institute of Technology (MIT). Di institusi pendidikan ini Nasr memperoleh pendidikan tentang ilmu-ilmu fisika dan matematika teoritis di bawah bimbingan Bertrand Russel dan mendapatkan gelar B.Sc pada tahun 1954. Beliau dikenal sebagai seorang filosof modern. Nasr banyak memperoleh pengetahuan tentang filsafat modern. Selain bertemu dengan Bertrand Russel, Nasr juga bertemu dengan seorang ahli metafisika bernama Geogio De Santillana. Dari kedua ini Nasr banyak mendapat informasi dan pengetahuan tentang filsafat timur, khususnya yang berhubungan dengan metafisika. Dia diperkenalkan dengan tradisi keberagamaan di timur, misalnya tentang Hinduisme. Selain itu Nasr juga diperkenalkan dengan pemikiranpemikiran para peneliti Timur, diantaranya adalah pemikiran Frithjof Schuon tentang perenialisme. Selain itu juga berkenalan dengan pemikiran Rene Guenon, A. K. Coomaraswamy, Titus Burchardt, Luis Massignon dan Martin Lings. Nasr banyak menghasilkan karya tulis antara lain, $A$ Youn Muslim's Guide to The Modern World, Islam and The Plight of Modern Man, Religion and The Order of Mature, An Introduction to Islamic Cosmological Doctrines; Ideals and Realities of islam; Islamic Stadies, Essays on Law and
Society, The Sciences, and Philosophy and Sufisme; The Encounter of Man and Nature; Science and Civilization in Islam; Sufi Essays; Islam and The Plight of Modern Man; Knowledge and The Sacred; Journal Milla wa Milla; Journal Iran; Studies in Comparative Religion; Religious Studies; The Islamic Quartelly; Hamdrard Islamicus; Word Sprituality. Islam tradisional adalah jalan dan pendekatan Nasr dalam memandang dunia, sebuah gagasan yang menerima wahyu Tuhan dalam hal isi maupun bentuk, menerima kutub al sittah, memandang thariqah atau tasawuf sebagai jantung pewahyuan Islam dan percaya tentang Islamisasi seni Islam dalam hubungannya dengan dimensi esoteric Islam (Mujahidin, 2003: 62).

\section{Problem Akademik yang Muncul dalam diskursus Estetika Islam Modern}

Problem akademik utama yang dihadapi di dalam estetika Sufistik dan estetika tauhidik adalah krisis spiritual dan melemahnya nilai-nilai agama yang ada di tengah-tengah masyarakat. Krisis ini juga disebut dengan dehumanisme yang disebabkan oleh menguatnya pandangan humanisme terutama humanism promethean. Di dalam American Humanist Association ditegaskan bahwa humanisme ini merupakan bentuk baru perkembangan filsafat yang menekankan prinsip kehidupan tanpa landasan ketuhanan maupun keyakinan supranatural dan menekankan kemampuan serta tanggung jawab individu seseorang sebagai kebaikan tertinggi bagi kemanusiaan. "Humanism is a progressive philosophy of live that, without theism and other supernatural beliefs, affirms our ability and responsibility to lead ethical lives of personal fulfillment that aspire to the greater good of humanity" (American Humanist Association, 2017)

Adapun humanism promethean atau insan promethean merupakan gambaran keakuan yang berdiri di atas kekuatannya sendiri, tidak membutuhkan pertolongan Tuhan sebagaimana digambarkan di dalam mitologi Yunani. 
Insan promethean adalah makhluk yang melawan dewa, mencuri api milik para dewata dan memberikannya kepada manusia. Promotheus siap menerima hukuman berat demi ikhtiarnya mengubah nasib manusia. Sosok yang bertekad mengatasi kodratnya yang terbatas dan tidak lengkap. Insan promethean menentukan kemajuan berdasarkan ekspektasi. Yang berkeyakinan akan citacita dan keinginan akan tercapai oleh kerja keras. Nasib harus diubah oleh diri sendiri, jangan menunggu atau berharap pada anugrah yang tak pasti (http//:pip.unpar.ac.id)

Krisis kemanusiaan yang disebabkan adanya pandangan antroposentris yang melihat manusia sebagai penentu segala-galanya bagi arah kehidupan manusia telah melemahkan kekuatan dimensi lain yang ada pada manusia, yaitu kekuatan ruhaninya. Akibat menguatnya humanisme ini kondisi internal individu dan sosial menjadi rapuh. Seni dan nilai-nilai keindahan tidak memiliki kekuatan batin. Problem akademik yang ditimbulkan dari falsafah ini nampaknya menjadi kegelisahan yang sama-sama dihadapi dalam konsepsi estetika sufistik maupun estetika tauhidik. Hanya saja, di dalam estetika tauhidik problem serius yang masih dihadapi adalah pandangan-pandangan hellinistik seperti mazhab epikuros, stoic, skeptic, elektisis, dan neoplatonik.

Persamaan yang ada pada estetika sufistik dan estetika tauhidik terletak pada landasan normatif, yaitu bahwa estetika Islam lebih menekankan adanya hubungan transendental, kepada Tuhan yang mencipta segala bentuk keindahan. Oleh sebab itu, Tuhan menjadi sumber segala keindahan, Tuhan itu indah dan mencintai keindahan. Perbedaan keduanya terletak pada pendekatan dan pemahaman objekobjek estetik. Dalam sudut pandang sufistik pengalaman langsung para subjek seni ditekankan untuk mencapai kesadaran batin, yaitu bagaimana seniman memahami, meresepsi, menghayati, dan mengekspresi semua proses kreatifitas dalam kesadaran ilahiyah, yaitu melalui praktek- praktek ritual secara langsung (riyadhah), mellui kontemplasi dan refleksi secara vertical kepada sumber pencipta Keindahan. Sedangkan dalam sudut pandang tauhid objek seni dipahami sebagai suatu manifestasi karya ekspresif sebagai bentuk perwujudan eksoterik berupa manifestasi tauhid dalam bentuk peribadatan karya kreatif seni (Al-Faruqi. 1986). Oleh karena Allah SWT harus diyakini dalam kesadarannya sebagai sumber keindahan (al-Jamāl) dan keindahan seni manusia berasal dari keindahan-Nya, maka manusia harus tunduk dihadapanNya. Ini adalah konsepsi yang menekankan penghambaan manusia, antara khaliq dan makhluq, dan bahwa Tuhan tidak bisa disamakan dengan makhluknya. Dia Esa tidak ada yang bisa menyamainya. Berdasarkan konsekuensi logis dari hubungan antara Pencipta dan hamba-Nya itu, maka manusia tidak dibolehkan membuat sesuatu yang tidak dibenarkan di dalam ajaran syariat Islam, karena itu akan membawa kepada Tasyrik, persekutuan atau persamaan.

Dalam aspek pendekatan keilmuan, estetika sufistik dengan orientasi spiritual batiniah barangkali hanya bisa didekati dan dipahami secara irfani, sebuah epistemologi pendekatan pencapaian secara mistik lewat ajaran tradisional secara langsung yaitu pengalaman spiritual, yaitu pengetahuan intuitif tentang hakikat spiritual yang diperoleh tanpa proses belajar. Yang kedua adalah "Gnostik" yang dikhususkan kepada pengetahuan tentang Allah yang dinisbahkan kepada "Gnostisime". Epitemologi Irfani mendasari pengetahuannya kepada kasyf, yaitu tersingkapnya rahasia-rahasia oleh/karena Tuhan. Oleh karena itu, 'irfan tidak diperoleh berdasarkan analisis terhadap teks, akan tetapi dari hati nurani yang suci, sehingga Tuhan menyingkapkan sebuah pengetahuan. Cara kerja irfani adalah proses pemahaman yang berangkat makna sebuah teks menuju lafaz teks tersebut. AlJabiri mengemukakan bahwa makna tersebut bisa terungkap pertama, dengan menggunakan cara apa yang disebut qiyas 'irfani, yaitu analogi makna batin yang diungkap dalam kasyf kepada makna lahir 
yang ada dalam teks. Dengan demikian, kendati pun proses pengetahuan irfani terletak pada aktivitas akal, yakni pada proses intuitif, akan tetapi proses pengetahuan ini dituntun oleh ramburambu al-Qur'an dan hadis. Ini dapat dilihat dari bagaimana proses pengungkapan makna dari sebuah teks (Haqqi, 2013).

Sementara estetika tauhidik sebagai falsafah keagamaan lebih mudah ditangkap melalui pendekatan epistemologi bayani, sebuah epistemologi yang bersumber dari teks-teks otoritatif Alquran dan hadis yang menjadi acuan. Menurut al-Jabiri bayani adalah metode pemikiran yang menekankan otoritas teks Arab (nash), secara langsung ataupun tidak langsung, dan dijustifikasi oleh akal kebahasaan yang digali lewat inferensi (istidlāl). Secara langsung artinya memahami teks sebagai pengetahuan dan mengaplikasikannya langsung tanpa perlu pemikiran. Secara tidak langsung berarti memahami teks sebagai pengetahuan yang mentah, sehingga memerlukan tafsir dan penalaran lebih mendalam. Meski demikian, hal ini bukan berarti akal dan nalar atau rasio dapat bebas menentukan makna dan maksudnya, tetapi tetap bersandar pada teks. Bayani, bila ditinjau dari segi historis kemunculannya, ia terbagi menjadi dua: pertama, kaedah atau dasardasar menafsirkan titah (khithāb), kata interpretasi atau penafsiran dikembalikan pada masa Nabi di saat para sahabat menafsirkan makna-makna dan ibarahibarah yang ada dalam al-Qur'an, atau paling tidak pada masakhulafa' alrasyidin, di saat umat bertanya kepada para sahabat tentang persoalan umat yang sulit dipecahkan. Kedua, syarat-syarat produksi titah, tema yang berhubungan dengan retotika, yang jelas ini muncul bersamaan dengan munculnya aliran politik dan perbedaan kalam setelah kejadian 'tahkim', di mana saat itu terjadi perdebatan yang bersifat "kalam sebagai saran penyebarluasan, memperoleh kemenangan, bantahan, dan permusuhan (Haqqi, 2013)

\section{Metodologi dan Kerangka Teori Diskursus Estetika Islam Modern}

Sebagaimana sudah dijelaskan pada sub pendekatan di atas bahwa pemahaman estetika sufistik hanya bisa didekati secara mistik tasawuf, maka metodologi yang digunakan adalah teknik-teknik yang diajarkan di dalam ilmu-ilmu batin atau penghayatan secara batin (al laduniyah) dan penyingkapan (kasyfiyyah). Makna esoteric yang terkandung di alam proses dan produk karya-karya seni itu dicapai melalui penghayatan kalbu, misalnya di dalam proses penciptaan kesenian taritarian sufi, selain melambangkan makna spiritual ia diproses sesuai dengan simbolsimbol abstrak kesucian. Symbol-simbol kesucian yang terlihat abstrak adalah bentuk lahir dari pembumian hal-hal yang bersifat ghaib, melalui cara inilah tarian sufi berusaha mengungkap kesadaran batin ke dalam bentuk lahir (kasyf).

Perbedaan metodologis estetika sufistik dengan Estetika tauhid terdapat di dalam perbedaan dimensi, antara batin dan lahir, antara yang abstrak dan yang nyata. Konsepsi estetika tauhid meskipun berusaha menghindari kesan kealaman dan kehidupan secara biologis, ia juga menampakkan bentuk-bentuk abstrak guna menunjukkan kesan abiotik. Al Faruqi menggagas hal ini dengan konsep abstraksi, struktur moduler, kombinasi suksesif, repetisi, dinamisme, dan intrikasi. Konsepsi ini berlaku di dalam berbagai manifestasi kesenian Islam, tidak terkecuali dalam seni ornamen, seni spasial maupun seni suara sebagaimana hal ini juga menonjol di dalam kaligrafi yang sering dipandang sebagai kesenian yang khas di dalam Islam.

Perbedaan teoritis kedua konsepsi adalah bahwa konsepsi estetika sufistik menggunakan teori pemahaman secara inner, yaitu tasawuf, dalam bahasa Arab ilmu ini dikenal dengan usaha untuk mengetahui bagaimana cara menyucikan jiwa, menjernihkan akhlak, membangun dhahir dan batin untuk memperoleh kebahagiaan abadi. Nasr sering menyebut pengetahuan ini dengan filsafat perennial, yaitu sebuah pandangan filosofis yang 
berkaitan dengan bagaimana cara menyucikan jiwa.

Kerangka teoritik estetika tauhidik adalah bahwa tauhid selain dipahami sebagai dasar kepercayaan-keimanan, tauhid juga dipahami sebagai pengalaman keagamaan dan pandangan dunia. Acuan pokok tauhid adalah Alquran yang dijadikan norma estetis, sebagai model kesenian, dan ikonografi. Tauhid sebagai pandangan dunia berikaitan dengan pandangan umum tentang realitas, kebenaran, dunia, ruang dan waktu, dan sejarah manusia. Sebagai prinsip utama di dalam estetika, seni tauhid berusaha menemukan esensi metafisis di dalam sebuah karya bendawi maupun abstraksi ke dalam bentuk nyata, "Art is the process of discovering within nature that metanatural essence and representing it in visible form" (Al Faruqi, 1986: 74-86).

\begin{tabular}{|c|c|c|}
\hline Acuan Epistemologi & Estetika Sufistik & Estetika Tauhidik \\
\hline $\begin{array}{l}\text { Latar Belakang } \\
\text { /Problem Akademik }\end{array}$ & $\begin{array}{l}\text { 1. Krisis Spiritualitas } \\
\text { masyarakat modern } \\
\text { 2. Kondisi internal } \\
\text { 3. Humanisme Sekuler }\end{array}$ & \begin{tabular}{|l|} 
1. Malaise Budaya \\
Modern \\
2. Kondisi internal umat \\
Islam \\
3. Hellinisme (Greco \\
Roman)
\end{tabular} \\
\hline Sumber & Pengalaman Langsung & Alquran dan Al Hadis \\
\hline Pendekatan & $\begin{array}{l}\text { Irfani (Mistik dan Ajaran } \\
\text { Tradisionalisme) }\end{array}$ & $\begin{array}{l}\text { Bayani (tekstual } \\
\text { Kebahasaan) }\end{array}$ \\
\hline Metodologi & $\begin{array}{ll}\text { 1. } & \begin{array}{l}\text { Al Laduniyah } \\
\text { (Penghayatan Batin } \\
\text { /mistik) }\end{array} \\
\text { 2. } & \begin{array}{l}\text { Al Kasyfiyyah } \\
\text { (penyingkapan) }\end{array}\end{array}$ & $\begin{array}{l}\text { 1. Ijtihadiyah melalui } \\
\text { Penghapusan bentuk- } \\
\text { bentuk Tasyrik } \\
\text { 2. Tauhid (Pemisahan } \\
\text { antara Khalik dan } \\
\text { Makhluk) } \\
\text { 3. Abstraksi } \\
\text { 4. struktur moduler } \\
\text { 5. kombinasi suksesif } \\
\text { 6. Repetisi } \\
\text { 7. dinamisme } \\
\text { 8. intrikasi. }\end{array}$ \\
\hline Kerangka Teori & $\begin{array}{l}\text { Tasawuf } \\
\text { Hakikat paling dalam }\end{array}$ & $\begin{array}{l}\text { Tauhid } \\
\text { 1. Pandangan Dunia } \\
\text { a. Dualitas } \\
\text { b. Ideasionalitas } \\
\text { c. Teleology } \\
\text { d. Kapasitas manusia } \\
\text { dan } \\
\text { Ketertundukan } \\
\text { alam } \\
\text { e. Tanggung jawab } \\
\text { dan Putusan } \\
\text { 2. Esensi Peradaban } \\
\text { a. Kesatuan } \\
\text { b. Rasionalitas } \\
\text { c. Toleransi } \\
\text { d. Dimensi Konten }\end{array}$ \\
\hline
\end{tabular}




\begin{tabular}{|c|c|c|}
\hline & & $\begin{array}{ll}\text { 1. } & \text { Prinsip } \\
& \text { Metafisika } \\
\text { 2. } & \text { Prinsip Etika } \\
\text { 3. } & \text { Prinsip } \\
& \text { Estetika }\end{array}$ \\
\hline $\begin{array}{l}\text { Fungsi dan Peran } \\
\text { Estetika }\end{array}$ & $\begin{array}{l}\text { 1. Estetika sebagai alat } \\
\text { partisipatif jiwa dalam } \\
\text { hubungannya dengan } \\
\text { Yang Transenden } \\
\text { 2. Sublimitas kesenian } \\
\text { transendental } \\
\text { ( Al Qaus al su-udi ) }\end{array}$ & $\begin{array}{l}\text { 1. Estetika sebagai } \\
\text { Pengalaman } \\
\text { Keagamaan } \\
\text { 2. Estetika sebagai } \\
\text { Pandangan Dunia } \\
\text { untuk Ta'abbudi }\end{array}$ \\
\hline $\begin{array}{l}\text { Kelompok Ilmu-ilmu } \\
\text { Pendukung }\end{array}$ & $\begin{array}{l}\text { 1. Ilmu-ilmu Tasawuf/ } \\
\text { Ma'rifat } \\
\text { 2. Teosofi (doktrin falsafah } \\
\text { agama dan mistisisme, } \\
\text { teosofi merupakan } \\
\text { pandangan bahwa semua } \\
\text { agama merupakan upaya } \\
\text { occult brotherhood agar } \\
\text { manusia dapat mencapai } \\
\text { kesempurnaan, sehingga } \\
\text { setiap agama } \\
\text { mempunyai kepingan } \\
\text { kebenaran). }\end{array}$ & $\begin{array}{l}\text { 1. Ilmu Bahasa } \\
\text { 3. Fiqih } \\
\text { 4. Falsafah kalam }\end{array}$ \\
\hline
\end{tabular}

Dalam sejarah kebudayaan Islam faktor-faktor yang menandai perkembangan dinamika budaya umat Islam ditunjukkan dengan semaraknya persoalan-persoalan kemanusiaan, sosial, ilmu pengetahuan, bahasa, seni, dan filsafat. Pada masa-masa berikutnya terutama pada zaman pertengahan dan modern dimana pengetahuan semakin pesat dan persoalan juga semakin bertambah, maka agama sangat dibutuhkan untuk memberikan justifikasi atau pembenaran terhadap perkembangan kebudayaan Islam tersebut. Aspek seni merupakan salah satu bidang kebudayaan yang menghadapi tuntutan pembenaran ini, karena sifatnya yang subjektif dan jika bersinggungan dengan agama khususnya yang berhubungan dengan persoalan dalildalil naqli kitab suci dan tradisi nabi dalam hal ini adalah hadis, maka pembenaran itu selalu berkaitan dengan interpretasi dantidak jarang masalah interpretasi ini membawa konsekuensi tersendiri meskipun juga membawa alternatif pilihan keyakinan.
Pada level ontologis dan aksiologis dasar-dasar seni selalu ditempatkan secara parallel dengan ajaran Islam itu sendiri, dimana wujud seni dan proses pencapaiannya harus sesuai dengan aturan syari'at, di sisi lain ia juga harus dipahami sebagai suatu media pencapaian spiritual. Bagi mereka yang beranggapan bahwa hakikat seni Islam dan estetikanya dapat dijelaskan apabila seseorang mengetahui bahwa esensi ajaran Islam ialah tauhid merupakan suatu kekeliruan, karena dengan berbekal pada anggapan seperti ini ternyata tidak mampu menjelaskan perkembangan seni Islam yang beraneka ragam. Selain itu adanya anggapan bahwa seni dan estetika Islam tidak pernah wujud karena pada level ontologis estetika Islam tidak sejalan dengan perkembangan artefaknya pada level aksiologis (Leaman, 2004).

Kompleksitas pandangan estetika Islam yang berkembang saat ini menunjukkan betapa interpretasi terhadap sumber sumber ayat dan hadis begitu luas dan produk artefak estetika Islam sudah 
diketahui bahwa semua orang hampir mengerti bahwa pada level ini perkembangan seni islam sudah berkembang jauh seantero dunia dimana kreativitas, ekspresi dan resepsi karyakarya peradaban Islam sudah melampaui batas-batas wilayah tertentu (Afrika, Asia, Eropa, Amerika) dan perbincangan tentang estetika Islam juga sudah dimulai.

Estetika sebagai sebuah ilmu yang mengkaji tentang segala hal yang berkaitan dengan keindahan dan semua aspek dari apa yang disebut dengan keindahan (Djelantik, 2001:7) dalam perkembangannya memiliki hubungan erat dengan disiplin ilmu lain seperti aspek pendidikan, sosial, etika, moral dan agama. Kajian tentang estetika agama dengan berbagai pendekatan pada gilirannya menjadi minat karena tolok ukur kebenaran suatu objek estetika dapat dilihat dari berbagai perspektif nilai. Di sisi lain problem sekulerisasi terhadap agama juga menjadi tugas tersendiri untuk mengembalikan nilai-nilai kehidupan agama yang terpisah antara realitas fisik dan batin. Dua dimensi ini menjadi kajian di dalam penelitian inidengan tujuan menemukan suatu pemahaman secara komprehensif tentang filsafat Islam.

\section{Respon Akademik}

Ide tentang Estetika Islam telah muncul sejak Al Ghazali melontarkan pandangan-pandangannya tentang sufisme yang dikaitkan dengan seni dan peradaban Islam meskipun pandangan Al Ghazali tersebut menuai kritik dari pandanganpandangan yang lain namun kritik terhadap merebaknya diskursus seni Islam yang datang dari kelompok orientalis sekuler tidak berangkat dari ajaran Islam itu sendiri sehingga mereka menurut Leaman gagal dalam memahami seni Islam. Mereka berusaha menjelaskan kelemahan dan kekurangan dari estetika Islam, bahwa seni Islam tidak utuh dan khas dengan ajaran serta kebudayaan agamanya itu sendiri.Respon akademik ini nampaknya menggoda para pemikir muslim untuk menempatkan persoalan estetika secara rasional walaupun sebenarnya dapat digambarkan secara utuh dalam warna sektarian.

Pada level epitemologis kesenian Islam nampaknya masih berada dalam ruang sakral keagamaan, hal ini disebabkan karena corak penafsiran yang berbeda maka sebagian atau semua kreator muslim belum mampu keluar dari habitatnya menuju alam kreatifitas berbasis pada pengetahuan sains, yang mampu menerjemahkan pandangan estetik ke dalam proses-proses kreatif khas Islam di antara kesenian-kesenian lain.

\section{Kesimpulan}

Berdasarkan hasil telaah pemikiran estetika tersebut di atas disimpulkan, Pertama, Estetika Islam berkembang dari penafsiran dan pemahaman ajaran agama itu sendiri. Munculnya estetika Sufistik dan estetika tauhidik merupakan wujud dari realitas estetik orang-orang Islam yang ingin mewujudkan Kebudayaan di tengah peradaban manusia. Estetika sufistik mencari terobosan melalui pendekatan spiritualitas batin, yaitu seni yang dijiwai dan dilandasi oleh semangat ruhani esoterik ajaran Islam. Adapun seni Tauhidik menekankan prinsip tauhid yaitu hubungan yang berbeda antara kreatifitas manusia dengan Ciptaan Tuhan karena ketentuan hukum yang menjadi dasar syari'ah.

Kedua, dinamika kebudayaan Islam terutama di dalam diskursus intelektual Islam sejak abad pertengahan hingga sekarang ini perkembangan pemikiran tentang seni keindahan Islam masih menunjukkan adanya kesadaran intelektual yang yang cukup terbatas di kalangan akademisi dan orang-orang Islam pada umumnya, namun demikian geliat sebagian kalangan akan perlunya pengembangan pemikiran bidang estetika ini mulai muncul karena tuntutan akademik tetapi belum menjadi suatu kebutuhan asasi. Model pemikiran sufistik dan tauhidik nampaknya merupakan hasil kesadaran budaya yang terus dipacu sesuai dengan pilihan dan keyakinan keberagamaan Islam itu sendiri. Namun temuan gambaran ini masih perlu dilanjutkan pada temuan lain model baru, 
yaitu gambaran estetika Islam yang lebih utuh, tidak partikular sebagaimana kedua gambaran estetika di dalam penelitian ini, saran ini dilandasi pemahaman bahwa Islam mencakup dimensi esoterik dan eksoterik sebagai kesatuan pandangan.

\section{Daftar Pustaka}

Abdullah, M. Amin, (2006). Islamic Studies Di Perguruan Tinggi. Yogyakarta: Pustaka Pelajar.

Al Faruqi, Ismail Raji, Louis Lamya, (1986). The Cultural Atlas of Islam. New York: MacMillan Publishing Company.

----------, 1996. Seni Tauhid, Esensi dan ekspresi Estetika Islam. Terj. Harsono Hadikusumo. Yogyakarta: Bentang Pustaka.

----------, 1992 Al Tauhid: It's Implication for Thought and Live. Virginia: IIIT.

Djelantik. A.A.M. 2001. Estetika Sebuah Pengantar. Bandung: MSPI.

Junaeidi, Deni. 2017. Estetika, Jalinan Subjek, Objek, dan Nilai. Yogyakarta: ArtCiv. 21

Mujahidin, M Farkhan. 2003. Estetika Dalam pandangan Ismail Raji Al Faruqi dan Seyyed Hossein Nasr. Tesis. Yogyakarta: IAIN SuKa.

Tim Penulis, 1995. Islam dan Kesenian. Yogyakarta: Majelis Kebudayaan Muhammadiyah Universitas Ahmad Dahlan dan Lembaga Litbang PP Muhammadiyah.

Leaman, Oliver. 2004. Estetika Islam, Menafsirkan Seni dan Keindahan. Bandung: Mizan.

Mansyur, Erwin, 2016. Fenomena Akulturasi Dan Sinkretisme Dalam Perspektif Arkeologi: Ragam Hias Di Kompleks Makam Bataliung Jeneponto, Sulawesi Selatan. Acculturation Phenomena and Syncretism in Archaeological Perspective: Ornamental Variety in Bataliung Tomb Complex, Jeneponto South Sulawesi. Jurnal Walennae. Vol 14. Nom 1. Hal. 45.

Nasr, Seyyed Hossein. 1987. Spiritualitas dan Seni Islam. Bandung: Mizan.
1972. Ideals and realities of Islam. London: Allen and Unwin. --. 1968. The Encounter Man and Nature. London: George Allen and Unwin Ltd.

--. Tt. Pengetahuan dan Kesucian. Yogyakarta: Pustaka Pelajar. -. 1994. Islam Tradisi di Tengah Kancah Dunia Modern. Terj Lukman Hakim. Bandung: Pustaka.

American Humanist Association. 2017. 1821 Jefferson Place, N W Washington DC 20036 202-2389088) acsess Senin 6 -2-2017. Pkl 07.14

Fabianus Sebastian Heatubun, Pr, Drs, SLL. Dalam pip.unpar.ac.id, Akses. Senin 6 jan 2017. 07.35)

https://afifrizqonhaqqi.wordpress.com/.../e pistemologi-bayani-irfaniburhani-abid-al-j.27 Jan 2013

https://www.referensimakalah.com > Biografi Islamil Raji al-Faruqi. Akses 26 September 2019, pkl 10.04. Ridwan, Kafrawi Ridwan (Ed), 1993. Ensiklopedia Islam, Jakarta: Ichtiar Baru Van Houve. Ummat, dalam rubrik "rampai' No.25 (tahun 1995).

Widodosyukronfa.blogspot.com > 2016/08 > sayyed-hossein-nasr akses, 1 oktober 2019 pkl 10.24)

angga-mardiansyah.blogspot.com akses, 4 oktober 2019 pkl 11.15. WIB

\section{Ucapan Terima Kasih}

Ucapan terimakasih disampai-kan kepada Lembaga Penelitian dan Pengabdian kepada Masyarakat Universitas Sebelas Maret (LPPM-UNS) yang telah mendukung dan mensponsori terlaksananya penelitian artikel ini dalam surat perjanjian nomor 516/UN27.21/PP/2019. Semoga penelitian ini dapat memberikan manfaat yang sebesar-besarnya kepada insan civitas akademik di manapun berada dan bagi masyarakat pada umumnya. 